\title{
Spontaneous Spinal Epidural Hematoma Causing Paraplegia: A Case Report
}

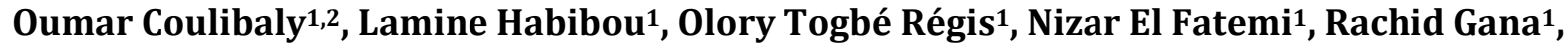 \\ Rachid Maaqili' ${ }^{1}$, Mohamed Jiddane ${ }^{3}$, Fouad Bellakhdar ${ }^{1}$ \\ ${ }^{1}$ Department of Neurosurgery, Hôpitallbn Sina, Rabat, Morocco \\ ${ }^{2}$ Department of Neurosurgery, Hôpital du Mali, Bamako, Mali \\ ${ }^{3}$ Department of Neuroradiology, Hôpitallbn Sina, Rabat, Morocco \\ Email: coulibalynch1@gmail.com
}

Received 15 June 2015; accepted 26 July 2015; published 30 July 2015

Copyright (C) 2015 by authors and Scientific Research Publishing Inc.

This work is licensed under the Creative Commons Attribution International License (CC BY).

http://creativecommons.org/licenses/by/4.0/

(c) () D Den Access

\begin{abstract}
A spontaneous spinal epidural hematoma without any identified etiology is a very rare entity. We report here a 44 years old woman admitted within our department for 04 days of severe back pain complicated rapidly of bilateral lower-limbs weakness and urinary retention. Neurological examination found a complete paraplegia (0/5 stergh), with incomplete sensory deficit below the T-10 level, bowel and bladder dysfunction, decreased deep and superficial reflex. MRI with different sequences showed a large epidural mass lesion with slightly high signal intensity on T1weighted images and heterogeneous low signal intensity on T2-weighted images from T11 to L1 suggesting an epidural hematoma. She underwent an urgent total laminectomy from T11 to L1 following by a complete removal of a large dark and compact epidural hematoma compressing the spinal cord. Operatively, there's no sign suggesting an AVM. Postoperative course was uneventful and she was discharged ten days after surgery with complete recovery.
\end{abstract}

\section{Keywords}

Spontaneous Spinal Epidural Hematoma, Spinal Cord Compression, MRI, Laminectomy

\section{Introduction}

Spontaneous spinal epidural hematoma (SSEH) is a relatively rare disease estimated to $0.3 \%$ to $0.9 \%$ of spinal epidural space-occupying lesions [1]. SSEH usually presents with sudden onset of neck or back pain followed by symptoms and signs of rapidly evolving nerve root and spinal cord compression [2]. So, its management requires prompt diagnosis and urgent treatment to prevent serious permanent neurological damages; this is why 
most surgeons advocate aggressive and early surgical intervention [3] [4]. Here, the authors describe a case of an 44 years old woman presented within our department with complete paraplegia revealing a compressive spinal epidural hematoma that was totally managed with good outcome four days after the initial presentation of her symptoms.

\section{Case Report}

A 44-year-old woman was admitted within our department for 04 days of severe back pain complicated rapidly of bilateral lower-limbs weakness and urinary retention. Neurological examination found a complete paraplegia (0/5 stergh), with incomplete sensory deficit below the T-10 level, bowel and bladder dysfunction, decreased deep and superficial reflex. She denied any past medical history or trauma. Magnetic Resonance Imaging (MRI) with different sequences showed a large epidural mass lesion compressing the spinal cord, with slightly high signal intensity on T1-weighted images and heterogeneous low signal intensity on T2-weighted images from T11 to L1 suggesting an epidural hematoma (Figure 1). The haemostasis profile was normal and she had no history of back trauma or vascular risk factors such as arterial hypertension, diabetes mellitus, dyslipidemia and other potential bleeding disorder or medication, which can induce such blood dyscrasia.

She underwent an urgent total laminectomy from T11 to L1 following by a complete removal of a large dark and compact epidural hematoma compressing the spinal cord. Operatively, there's no sign suggesting an arterio veinous malformation (AVM). The hematoma was evacuated, the cord adequately decompressed, and the tissue was sent for histology. Postoperative course was uneventful and she was discharged ten days after surgery with complete recovery.Histological examination revealed engorged vessels, with hemorrhage and clot in the extra vascular tissues, but no features to suggest inflammation or tumor in the biopsy.

A postoperative MRI study (Figure 2) showed a total evacuation of the epidural hematoma and continues to feel well since ten months.

\section{Discussion}

A spontaneous spinal epidural hematoma (SSEH) is a very rare condition that may be managed promptly to prevent serious permanent neurological damages [3]. The spontaneous development of such hematomas is most frequent after the fourth or fifth decade [5] [6]. However, it has been reported to occur in all age groups, but it is a very rare clinical entity in children [7]-[9]. Certain precipitating factors, including anticoagulant therapy for prosthetic cardiac valves, therapeutic thrombolysis for acute myocardiac infarction, hemophilia B, factor XI

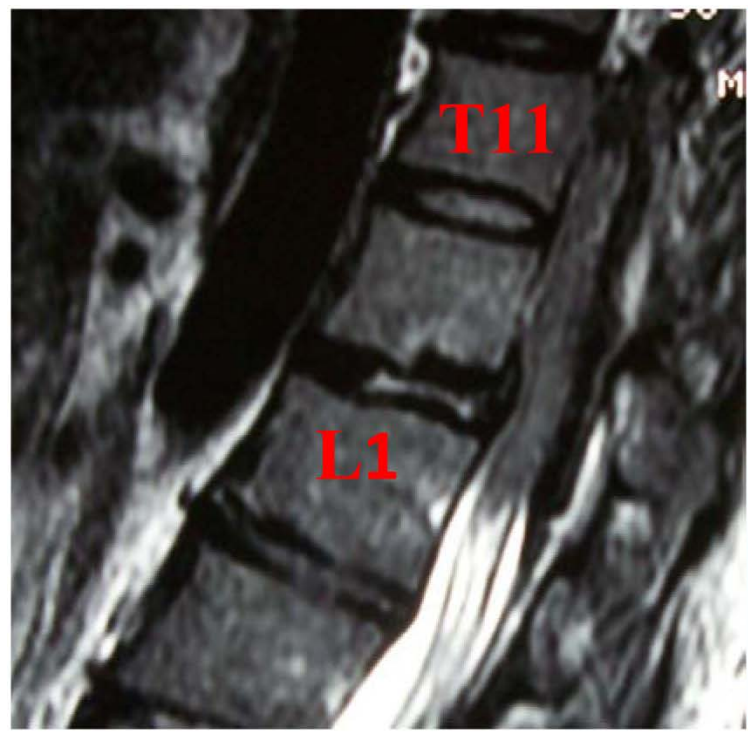

(a)

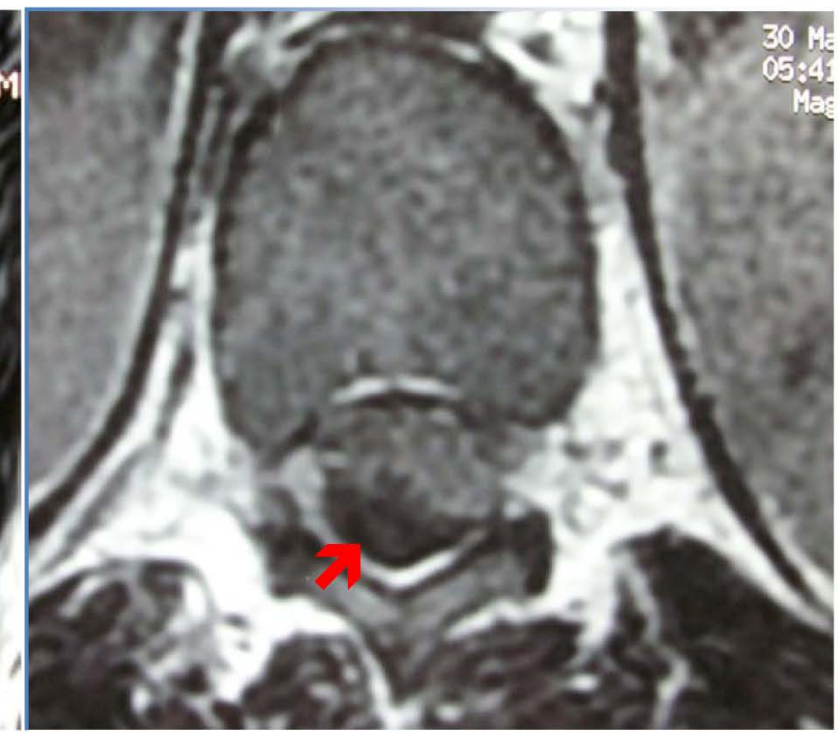

(b)

Figure 1. PreoperativeT2-weighted MRI shows a spontaneous spinal epidural heterogeneous low signal intensity hematoma located from T11 to L1 (a) and spinal compression on the dorsal and right lateral sides ( $7 \mathrm{~b}$ ). 


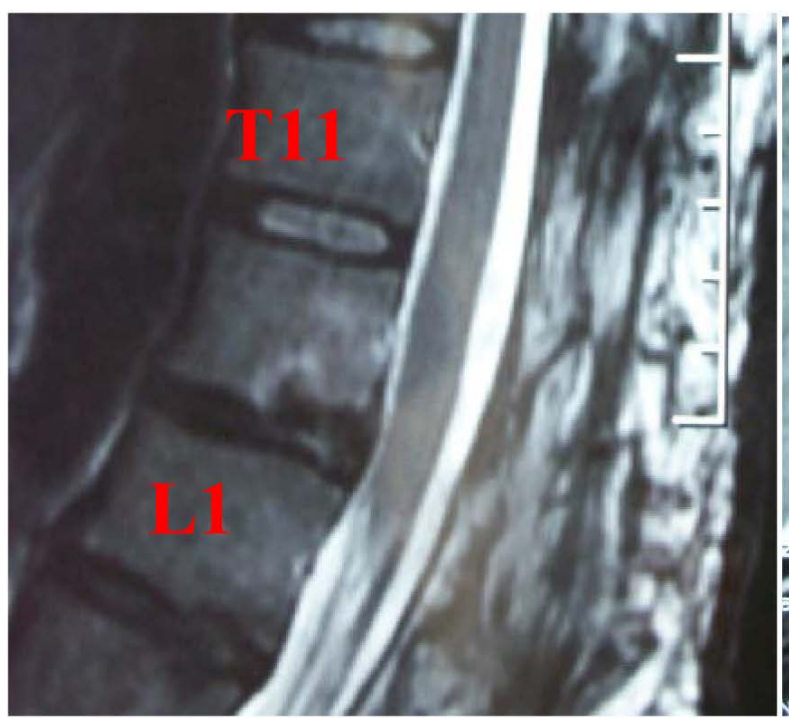

(a)

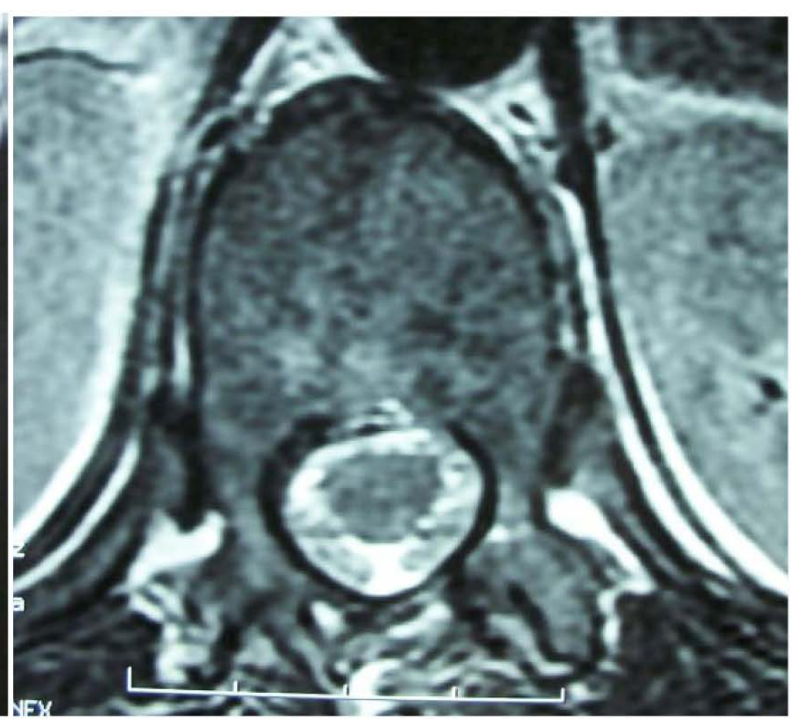

(b)

Figure 2. Postoperative T2 weighted MRI shows a complete decompression of the spinal cord (a) (b).

deficiency, long-term aspirin using as a platelet aggregation inhibitor, and vascular malformation, are suggested to be correlated with spontaneous spinal epidural hematomas [10] [11]. It is also a rare occurrence during pregnancy, with only six cases reported in the literature [12]. Statistically, idiopathic cases account for approximate $40 \%$ of all cases [13] [14]. The most common site of a spontaneous spinal epidural hematoma is the cervicothoracic region or thoracolumbar region [7] [15]. Up to now, there have been disputes about the origin of these hematomas. Most researchers assert that SSEHs arise from the epidural venous plexus in the spinal epidural space [13], [16]-[18], although several authors have proposed the spinal epidural arteries as a source of hemorrhage [19]. Proof of either is difficult because, in most cases, there is lack of angiographic documentation of the lesion and, even with open surgical exploration and clot removal, the specific cause is often not evident [1] [20]. The spinal epidural space contains an extensive internal venous plexus, which communicates with the external vertebral venous plexus. Together, they form the Batson plexus, a valveless low-pressure system that provides an alternate route for venous return from other areas of the body and assists in regulating volume and pressure changes between the intrathoracic, intraabdominal, and intraspinal systems [6] [9] [14] [21]. Valsalva maneuvers, such as straining, coughing, or lifting, increase intra abdominal and intrathoracic pressure [6] [22]. This, in turn, is transferred to the spinal epidural venous system and is thought to contribute to the rupture and hemorrhage of the epidural venous vessels [14] [23]. The typical clinical presentation of SSEH is the sudden onset of severe back, neck or inter scapular pain followed by progressive neurological deficits (paraparesis or quadriparesis). These signs are depending on the level of the lesion and the nerve root [11] [16]. Currently, MRI is considered as the first choice diagnostic method for SSEH [4]. It typically shows biconvex hematomas in the epidural space with well-defined border stapering superiorly and inferiorly. Subacute hematomas show characteristic high signal intensity on T1-weighted images, low signal intensity on theT2 weighted images [7] [23]. A Computed Tomography (CT) scan should be obtained if MRI is unavailable or contraindicated [23] [24]. The differential diagnosis of spontaneous spinal epidural hematoma includes an acute herniated intervertebral disc, acute ischemia of the spinal cord, epidural tumor or abscess, spondylitis, transverse myelitis, or even a dissecting aortic aneurysm and acute myocardial infarction [25]. Early surgical intervention is the general treatment for spontaneous spinal epidural hematomas [26]. The procedure includes decompressive laminectomy and hematoma removal. In cases with incomplete neurological deficits, the operation should be performed within 48 hours of the onset of the initial symptoms [3]. If the initial neurological deficits are complete, the operation should be performed within 36 hours [3]. Conservative treatment as also been documented, and it was employed only when neurological deficits improved in the early phase or with the coexistence of coagulopathy [27].

Therapeutic outcome depends on the time between the onset of symptoms and surgical decompression and the level of preoperative neurological deficit; that means, patients with severe neurological deficits preoperatively have poor clinical outcomes [15] [25] [28]. In a review of 330 cases of SSEH in the literature, some authors 
conclude that those patients with complete preoperative sensorimotor loss are at high risk for persisting neurological deficits after surgical decompression [25]. Other studies also showed that, of the patients with complete neurological deficits preoperatively, none returned to normal [29]. In contrast, a review of 158 cases of SSEH treated surgically found that complete sensorimotor recovery occurred in $41.9 \%, 26.1 \%$, and $11.3 \%$ of patients with incomplete sensorimotor, incomplete sensory but complete motor, and complete sensorimotor deficits, respectively [30].

In our case, the spinal cord decompression was done 04 days (96 hours) after the onset of symptoms and our patient recovered completely. Of course, the degree of recovery after surgical treatment depends on the severity of neurological deficits before treatment, but through this rare anecdotic case, we invite all the surgeons to operate all the SSEHs whatever their neurological status and the time of admission.

\section{Conclusion}

SSEH with no predisposing factors is among the rare causes of spinal cord compression, which requires early recognition, diagnosis, and surgical intervention without delay to prevent morbidity. Our patient had complete motor and slight incomplete sensory deficits at presentation, and even though she underwent surgical decompression 04 days from symptom onset, she had recovered successfully and continues to be very well since ten months. However, we conclude that patients with SSEH with our without complete neurological deficit must undergo early surgical decompression regardless of the time from symptom onset.

\section{Acknowledgements}

We would like to thank Mrs. Barry Najah for her supports for this manuscript.

\section{References}

[1] Alexiadou-Rudolf, C., Ernestus, R.I., et al. (1998) Acute Nontraumatic Spinal Epidural Hematomas. An Important Differential Diagnosis in Spinal Emergencies. Spine, 23, 1810-1813. http://dx.doi.org/10.1097/00007632-199808150-00018

[2] Lo, C.C., Chen, J.Y., Lo, Y.K., Lai, P.H. and Lin, Y.T. (2012) Spontaneous Spinal Epidural Hematoma: A Case Report and Review of the Literatures. Acta Neurologica Taiwan, 21, 31-34.

[3] Chen, C.L., Lu, C.H. and Chen, N.F. (2009) Spontaneous Spinal Epidural Hematoma Presenting with Quadriplegia after Sit-Ups Exercise. American Journal of Emergency Medicine, 27, 1170.e3-1170.e7. http://dx.doi.org/10.1016/j.ajem.2009.01.003

[4] Shin, J.J., Kuh, S.U. and Cho, Y.E. (2006) Surgical Management of Spontaneous Spinal Epidural Hematoma. European Spine Journal, 15, 998-1004. http://dx.doi.org/10.1007/s00586-005-0965-8

[5] Aksay, E. (2008) Kemergency Department: Spontaneous Spinal Epidural Hematoma. American Journal of Emergency Medicine, 26, 835.e3-e5.

[6] Ravid, S., Schneider, S. and Maytal, J. (2002) Spontaneous Spinal Epidural Hematoma: An Uncommon Presentation of a Rare Disease. Child's Nervous System, 18, 345-347. http://dx.doi.org/10.1007/s00381-001-0540-5

[7] Lim, J.J., et al. (2008) Spontaneous Spinal Epidural Hematoma in Infant. Journal of Korean Neurosurgical Society, 44, 84-87. http://dx.doi.org/10.3340/jkns.2008.44.2.84

[8] Poonai, N., Rieder, M.J. and Ranger, A. (2007) Spontaneous Spinal Epidural Hematoma in an 11-Month-Old Girl. Pediatric Neurosurgery, 43, 121-124. http://dx.doi.org/10.1159/000098385

[9] Wittebol, M.C. and van Veelen, C.W. (1984) Spontaneous Spinal Epidural Hematoma. Clinical Neurology and Neurosurgery, 86, 265-270. http://dx.doi.org/10.1016/0303-8467(84)90287-7

[10] Bisson, E.F., Dumont, T. and Tranmer, B. (2007) Spontaneous Spinal Epidural Hematoma in a Child with Hemophilia B. Canadian Journal of Neurological Sciences, 34, 488-490. http://dx.doi.org/10.1017/S0317167100007423

[11] Yu, H.P., Fan, S.W., Yang, H.L., Tang, T.S., Zhou, F. and Zhao, X. (2007) Early Diagnosis and Treatment of Acute or Subacute Spinal Epidural Hematoma. Chinese Medical Journal, 120, 1303-1308.

[12] Bose, S., Ali, Z., Rath, G.P. and Prabhakar, H. (2007) Spontaneous Spinal Epidural Hematoma: A Rare Cause of Quadriplegia in the Post-Partum Period. British Journal of Anaesthesia, 99, 855-857. http://dx.doi.org/10.1093/bja/aem265

[13] Liu, Z., Jiao, Q., Xu, J., et al. (2008) Spontaneous Spinal Epidural Hematoma: Analysis of 23 Cases. Surgical Neurology, 69, 253-260. http://dx.doi.org/10.1016/j.surneu.2007.02.019 
[14] Szkup, P. and Stoneham, G. (2004) Spontaneous Spinal Epidural Haematoma during Pregnancy: Case Report and Review of the Literature. The British Journal of Radiology, 77, 881-884.

[15] Borm, W., Mohr, K., Hassepass, U., Richter, H.P. and Kast, E. (2004) Spinal Hematoma Unrelated to Previous Surgery: Analysis of 15 Consecutive Cases Treated in a Single Institution within a 10-Year Period. Spine, 29, E555-E561. http://dx.doi.org/10.1097/01.brs.0000147743.46315.8b

[16] Baek, B.S., et al. (2008) Spontaneous Spinal Epidural Hematoma. The Korean Neurosurgical Society, 44, 40-42. http://dx.doi.org/10.3340/jkns.2008.44.1.40

[17] Colsy, M., Argote, C., Raimbault, M. and Touchard, P. (2007) Spontaneous Spinal Epidural Haematoma Causing Rapid Flaccid Paraplegia in a Healthy 25-Year-Old Patient (French). Annales Françaises d'Anesthésie et de Réanimation, 26, 608-611. http://dx.doi.org/10.1016/j.annfar.2007.03.010

[18] Guzel, A., Simsek, O., Karasalihoglu, S., Kucukugurluoglu, Y., Acunas, B., et al. (2007) Spontaneous Spinal Epidural Hematoma after Seizure: A Case Report. Clinical Pediatrics, 46, 263-265. http://dx.doi.org/10.1177/0009922806289427

[19] Solheim, O., Jorgensen, J.V. and Nygaard, O.P. (2007) Lumbar Epidural Hematoma after Chiropractic Manipulation for Lower Back Pain: Case Report. Neurosurgery, 61, E170-E171; Discussion E171.

[20] Clarke, D.B., Bertrand, G. and Tampieri, D. (1992) Spontaneous Spinal Epidural Hematoma Causing Paraplegia: Resolution and Recovery without Surgical Decompression. Neurosurgery, 30, 108-111. http://dx.doi.org/10.1227/00006123-199201000-00019

[21] Vitali, A.M. and Steinbok, P. (2008) Spontaneous Spinal Epidural Hematoma Following Weight Lifting. Canadian Journal of Neurological Sciences, 35, 262-264. http://dx.doi.org/10.1017/S0317167100008763

[22] Marinella, M. and Barsan, W.G. (1996) Spontaneously Resolving Cervical Epidural Hematoma Presenting with Hemiparesis. Annals of Emergency Medicine, 27, 514-517.

[23] Fujiwara, H., Oki, K., Momoshima, S. and Kuribayashi, S. (2005) PROPELLER Diffusion-Weighted Magnetic Resonanace Imaging of Acute Spinal Epidural Hematoma. Acta Radiologica, 146, 539-542.

[24] Riaz, S., Jiang, H., Fox, R., et al. (2007) Spontaneous Spinal Epidural Hematoma Causing Brown-Sequard Syndrome: Case Report and Review of the Literature. The Journal of Emergency Medicine, 33, 241-244. http://dx.doi.org/10.1016/j.jemermed.2007.02.032

[25] Groen, R.J. and Van Alphen, H.A. (1996) Operative Treatment of Spontaneous Spinal Epidural Hematomas: A Study of the Factors Determining Postoperative Outcome. Neurosurgery, 39, 494-508.

[26] Matsumura, A., Namikawa, T., Hashimoto, R., Okamoto, T., et al. (2007) Clinical Management for Spontaneous Epidural Hematoma: Diagnosis and Treatment. The Spine Journal, 8, 534-537. http://dx.doi.org/10.1016/j.spinee.2007.01.009

[27] Tailor, J., Dunn, I.F. and Smith, E. (2006) Conservative Treatment of Spontaneous Spinal Epidural Hematoma Associated with Oral Anticoagulant Therapy in a Child. Child's Nervous System, 22, 1643-1645. http://dx.doi.org/10.1007/s00381-006-0220-6

[28] Hsieh, C.T., Chang, C.F., Lin, E.Y., et al. (2006) Spontaneous Spinal Epidural Hematomas of Cervical Spine: Report of 4 Cases and Literature Review. The American Journal of Emergency Medicine, 24, 736-740. http://dx.doi.org/10.1016/j.ajem.2006.01.025

[29] Song, K.J. and Lee, K.B. (2005) The Poor Outcome of the Delayed Diagnosis of Acute Spontaneous Spinal Epidural Hematoma: Two Cases Report. The Korean Academy of Medical Sciences, 20, 331-334. http://dx.doi.org/10.3346/jkms.2005.20.2.331

[30] Foo, D. and Rossier, A.B. (1981) Preoperative Neurological Status in Predicting Surgical Outcome of Spinal Epidural Hematomas. Surgical Neurology, 15, 389-401. http://dx.doi.org/10.1016/0090-3019(81)90178-6 